\title{
Utilization of waste chloroorganic compounds
}

\author{
Jerzy Myszkowski, Eugeniusz Milchert, Marcin Bartkowiak, Robert Pełech* \\ West Pomeranian University of Technology, Szczecin, Institute of Chemical Organic Technology, ul. Pulaskiego 10, \\ 70-322 Szczecin, Poland, e-mail: robert.pelech@zut.edu.pl
}

\begin{abstract}
Efficient methods of utilization of waste chloroorganic compounds coming from waste water and the waste streams formed e.g. in the production of vinyl chloride by dichloroethane method and in the production of propylene oxide by chlorohydrin method have been presented. First the separation of chloroorganic wastes by the adsorption methods has been described in the article. Three valuable methods of chlorocompounds utilization have been then discussed. The first one is isomerization of 1,1,2-trichloroethane to 1,1,1trichloroethane as the valuable product with less toxicity than a substrate. The second method is ammonolysis of waste 1,2-dichloropropane and 1,2,3-trichloropropane. The third described method is chlorolysis. This method can be used for the utilization of all types of waste chloroorganics.
\end{abstract}

Keywords: adsorption, amonolysis, chloroorganic compounds, isomerization, chlorolysis.

\section{INTRODUCTION}

Several waste streams containing chloroorganic compounds are generated in the production of vinyl chloride by dichloroethane method and in the production of propylene oxide by chlorohydrin method, ${ }^{\mathbf{1} 2}$. These streams are most often the distillation heads and tails, but the significant amounts of persistent organic pollutants (POPs) containing chloride are emitted in the streams of wastewater released to the environment.

Two main streams of liquid chloroorganic wastes are generated in the vinyl chloride production plant. The first one is the heads and tails obtained during the distillation of the so-called "light fraction" and "heavy fraction", which were separated during the purification of 1,2dichloroethane and the residues from the quick cooling column (after the pyrolysis). The second stream is the distillate from the expelling column, obtained in the stream-stripping of the water phase from the oxychlorination. The composition of these streams is shown below in table 1 .

1,2-Dichloropropane and bis(1-chloro-2-propyl) ether are the main by-products formed during the stage of chlorohydroxylation in the propylene oxide plant. The scheme of their formation is shown below:

- formation of 1,2-dichloropropane<smiles>C=CC</smiles><smiles>CC(Cl)CCl</smiles>

- reactions of bis(1-chloro-2-propyl) ether formation<smiles></smiles>

The typical procedures of the utilization of waste chloroorganic compounds are the incineration or destructive oxidation (if they are in wastewater). These methods are effective but they are not economically efficient, because many valuable chemical compounds are definitely destroyed.

Moreover, the incineration of chloroorganics can generate the emission of dangerous dioxins and other toxic persistent organic pollutants.

The efficient and industrially verified methods of utilization of waste chloroorganic compounds formed in the production of vinyl chloride (via dichloroethane) and propylene oxide (via chlorohydrine) have been proposed in this publication.

\section{Separation of chloroorganic compounds from the wastewater \\ The stream of environmentally noxious wastewater is generated during the production of vinyl chloride ${ }^{\mathbf{1 , 2}}$. This stream contains chloroorganics in the amount of $4-5 \mathrm{~kg}$ per $1 \mathrm{Mg}$ of wastewater. Application of the two-stage purification of the wastewater stream allows the complete removal of the chloroorganic pollutants.}

Table 1. The composition of the main waste streams in the vinyl chloride installation [wt\%]

\begin{tabular}{|lr|lr|lr|}
\hline Heads & & Tails & & Distillate \\
\hline 1,1,2-trichloroethane & 35.5 & 1,1,2-trichloroethane & 36.5 & chloroform & 71.0 \\
1,2-dichloroethane & 30.5 & $1,1,2,2$-tetrachloroethane & 14.1 & 1,2-dichloroethane & 26.5 \\
1,1,2,2-tetrachloroethane & 11.2 & perchloroethylene & 11.0 & cis-1,2-dichloroethylene & 0.5 \\
1,1,1,2-tetrachloroethane & 6.7 & pentachloroethane & 10.8 & CCl & 0.5 \\
perchloroethylene & 10.5 & 1,2 -dichloroethane & 6.5 & 1,1-dichloroethane & 0.5 \\
pentachloroethane & 4.1 & $1,1,1,2$-tetrachloroethane & 5.3 & vinyl chloride & 0.5 \\
trichloroethylene & 1.2 & polymers \& tars & 15.8 & vinylidene chloride & 0.5 \\
\hline
\end{tabular}


In the first stage the steam stripping is applied to the waste stream. Concentration of pollutants decreases to the level of 5-10 g per $1 \mathrm{Mg}$ of wastewater.

The second stage of the wastewater purification is the adsorption on the fixed bed adsorbent (activated carbon), which decreases the level of pollutants concentration to $1 \mathrm{mg}$ per $1 \mathrm{Mg}$ and below ${ }^{3,4}$.

Application of the integrated system of purification consisted of the steam stripper and active carbon adsorber allows to recover and utilize approx. $900 \mathrm{Mg}$ /year of chloroorganic compounds due to the non-destructive character of those operations (stripping - adsorption). This procedure can be applied to the most noxious wastes from the production of propylene oxide by chlorohydrin method. In this case the steam stripping is not very efficient due to the low volatility of pollutants. However, the adsorption process can be integrated with the adsorber regeneration by washing the active carbon bed with the lowboiling solvent. In the case of 1,2-dichloropropane and bis(2-chloroisopropyl) ether application of acetone results in a high degree of the regeneration of the fixed bed. This system allows to recover approx. $1920 \mathrm{Mg} /$ year of useful chloroorganic compounds from the epichlorohydrin plant and approx. $820 \mathrm{Mg} /$ year from the propylene oxide plant. The recovery installations of the chloroorganic compounds from the wastewater generated during the production of epichlorohydrin and propylene oxide (heavy chloroorganic compounds) and vinyl chloride (light chloroorganic compounds) are shown below in Figures 1 and 2.

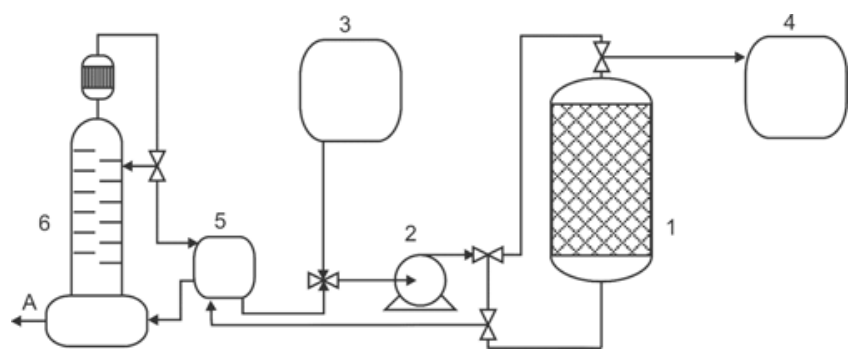

Figure 1. The diagram of the heavy chloroorganic compounds recovery installation, 1 - adsorber, 2 - pump, 3, 4, 5 - reservoir of waste, eluent and acetone adequate, 6 - distillation column, A - recovered chloroorganic compounds

Heavy chloroorganic compounds are recovered by the adsorption onto activated carbon (1) and subsequently washing the bed with acetone. Next the acetone is distilled out in column (6). The desorbed chlorocompounds remain in the distillation pot. The distilled acetone is recirculated to the tank (5) and next to the adsorber (1).

The steam stripping is applied for the recovery of light chloroorganic compounds (Fig. 2) followed by adsorption in the battery of fixed bed adsorbers (1) filled with activated carbon. Desorbate is pumped back to the stripping column (3) and conducted together with the steam in the bottom of the column. The condensate is cooled and separated in the phase separator (4). The organic phase is collected from the separator and consists of the recovered chloroorganic compounds.

The chemical compounds recovered from the wastewater can be utilized to the useful products using one of the methods proposed below.

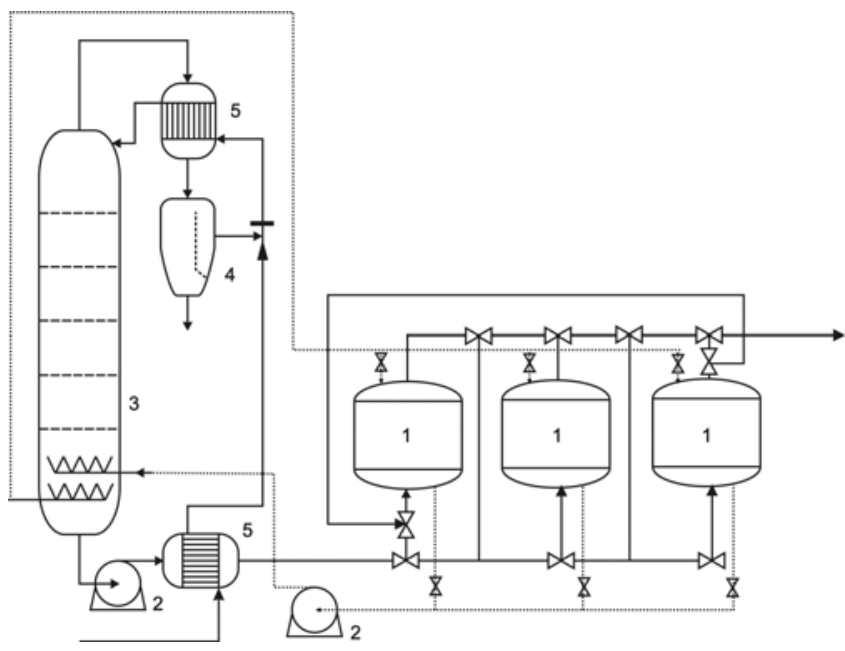

Figure 2. The diagram of the light chloroorganic compounds recovery installation, 1 - adsorber, 2 - pump, 3 - stripping column, 4 - separator, 5 - heat exchanger, -.... steam line, - waste line

\section{Isomerization}

Isomerization is an efficient method to obtain 1,1,1trichloroethane (111TCE) form waste 1,1,2trichloroethane (112TCE). 111TCE is a widespread and popular chloroorganic solvent due to its relatively low toxicity. Isomerisation of $112 \mathrm{TCE}$ is carried out in two steps $^{5,6}$. The first step is a partial dehydrochlorination of 112TCE to 1,1-dichloroethylene (VDC) in alkali solution $(\mathrm{NaOH})$ :

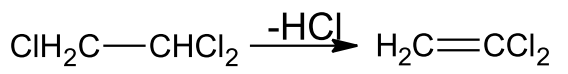

The optimal conditions for this reaction are as follows: the concentration of $\mathrm{NaOH}$ is $10 \mathrm{wt} . \%$, the temperature of the reaction mixture is $70-80^{\circ} \mathrm{C}, 112 \mathrm{TCE} / \mathrm{NaOH}$ molar ratio is $1.05-1.1$. VDC obtained in this step is distilled out from the reaction mixture. In the next step $\mathrm{HCl}$ reacts with VDC in the presence of the catalyst and $111 \mathrm{TCE}$ is formed.

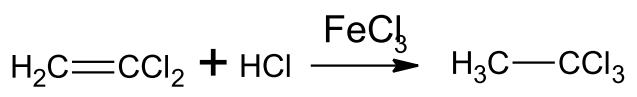

Addition of hydrogen chloride is carried out at low temperature $\left(20-25^{\circ} \mathrm{C}\right)$ in the presence of $\mathrm{FeCl}_{3}$ as homogenous catalyst dissolved in the reaction mixture. Optimal $\mathrm{FeCl}_{3}$ concentration is $0.3 \mathrm{wt} . \%$.

In a similar manner the waste 1,2-dichloropropane (12DCP) can be converted into 1,3-dichloropropane (13DCP), which can be used as a valuable raw material in the production of 1,3-diaminopropane and 1,3dihydroxypropane. In this case isomerization can be carried out in the one-step process. The reaction is catalysed with aluminium chloride as shown below:<smiles>CCC(Cl)CCCCCCl</smiles>

\section{Ammonolysis}

Ammonolysis can be used for the utilization of waste 1,2-dichloropropane and 1,2,3-trichloropropane obtained as by-products in the process of the production of glycerol epichlorohydrin. Ammonolysis can be also useful for the 
utilization of waste polyamides, PET and many other chemical species i.e. pesticides and other POPs (persistent organic pollutants).

Ammonolysis of waste 1,2-dichloropropane is a very interesting process due to the numerous applications of the products obtained in this reaction. The main product is 1,2-diaminopropane, a valuable raw material for many organic syntheses. This process can be carried out using ammonia in water, but more preferably using liquid and gaseous ammonia as ammonolytical agent. The ammonolysis process of 12DCP can be described by the following reaction equations ${ }^{7,8}$ :
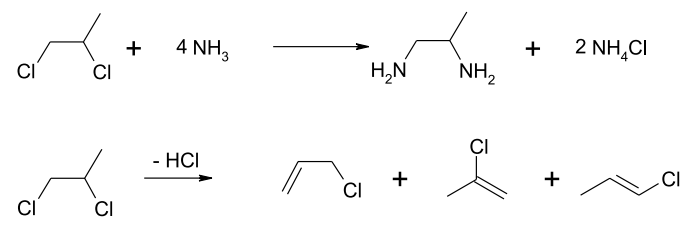

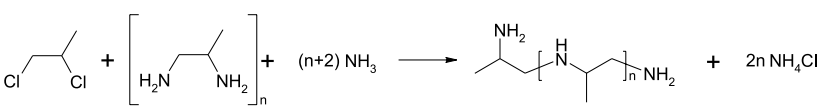

Two- side reactions occurs in the described process. The first one is dehydrochlorination of 12DCP to 3-, 2and 1-chloropropene. The second one is the alkilation, where 1,2-diaminopropane (12DAP) formed in situ reacts with $12 \mathrm{DCP}$ due to the higher basicity of 12DAP than an ammonia. It results in forming of polypropyleneamines, especially dipropylenetriamines and tripropylenetetraamines. They are also valuable products for organic chemistry. The process parameters can be optimized to achieve the highest selectivity of 12DAP or polyamines, depending on the needs. Moreover, the amount of chloropropenes can be easily reduced in this way.

The diagram of the installation of 112DCP ammonolysis using liquid ammonia as the ammonolytical agent was shown below in Fig. 3.

Both the 1,2-diaminopropane and polypropyleneamines are valuable chemical compounds and they found many applications in modern organic synthesis e.g. in petrochemistry, textile industry, plastics and surfactants production 9,10 . One of the 12DAP applications is the pro-

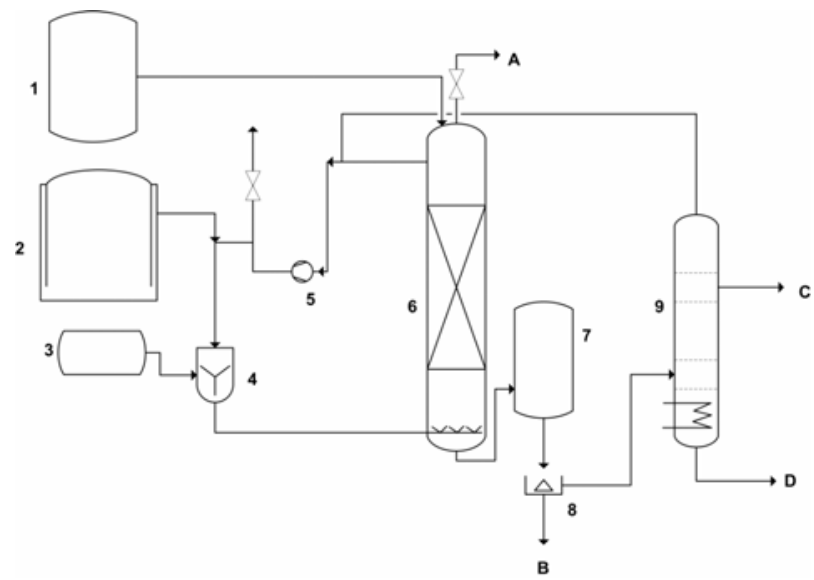

Figure 3. The diagram of 1,2-dichloropropane ammonolysis installation: 1 - DCP tank, 2 - Ammonia tank, 3 - catalyst, 4 - mixer, 5 - ammonia compressor, 6 - ammonolysis reactor, 7 - raw product reservoir, 8 - centrifugal separator, 9 - distillation column, A - purge gas stream, $\mathrm{B}-\mathrm{NH}_{4} \mathrm{Cl} /$ catalyst, $\mathrm{C}$ - 1,2-diaminopropane, $\mathrm{D}$ - polyamines duction of thionourethane, as shown below in the following reaction equations:

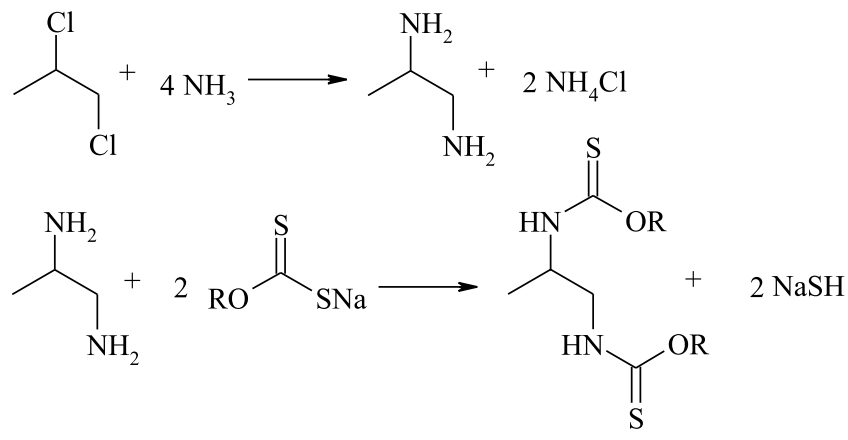

\section{Chlorolysis}

Practically all the chloroorganic wastes can be utilized by chlorolysis. As the result of this process tetrachloromethane and PER can be obtained ${ }^{1}$. The number of tetrachloromethane applications decreased in the last years, especially for the sake of stopping the production of freons 11,12 and 13 . That is why the chlorolysis of chloroorganic wastes is conducted to produce perchloroethylene as the main product.

Some secondary wastes are produced during the chlorolysis of waste chloroorganic compounds. The socalled "hexes" are produced: hexachlorobenzene (HCB), hexachlorobutadiene $(\mathrm{HCBu})$ and hexachloroethane (HCE). There are some additional methods of the utilizaton of those "hexes". HCB as a toxic POP ${ }^{11}$ may be used in the production of pentachlorophenol and sodium pentachlorophenolate, or dechlorinated reductively ${ }^{12}$. $\mathrm{HCBu}$ may be converted into HCE, dichloromaleic anhydride or used as a solvent, or dechlorinated ${ }^{13}$. HCE may be utilized as antipirene, plasticizer or the component of insecticidal or fungicidal agents.

\section{LITERATURE CITED}

1. Milchert, E. (1997). Technologies of the production of chloroorganic compounds. Waste utilization. Szczecin, WUPS. (in Polish)

2. Milchert, E., Bartkowiak, M., Pełech, R. (2008). Progress in selected technologies of chemical industry. Szczecin, WUPS. (in Polish)

3. Pełech, R., Milchert, E. \& Wróbel, R. (2006). Adsorption dynamics of chlorinated hydrocarbons from multi-component aqueous solution onto activated carbon. J. Hazard. Mater. 137, 1479 - 1487. DOI: 5551 10.1016/j.jhazmat.2006.04.023 S0304-3894(06)00394-3.

4. Pełech, R., Milchert, E. \& Bartkowiak, M. (2006). Fixedbed adsorption of chlorinated hydrocarbons from multi-component aqueous solution onto activated carbon. Equilibrium column model. J. Colloid Interf. Sci. 296, 458 - 464. DOI: 11656 10.1016/j.jcis.2005.09.020 S0021-9797(05)00954-9.

5. Myszkowski, J., Pełech, R., Wróblewska, A. \& Milchert, E. (2006). Creating the environmentaly friendly technologies by utilization of waste and wastewater. Przem. Chem. 85, 638 - 640. (in Polish)

6. Myszkowski, J., Milchert, E., Paździoch, W. \& Pełech, R., (2007). Formation of environmental friendly technology by sewage and by-products utilization, P.J. Chem. Tech. 9 (3), 118 -121 .

7. Bartkowiak, M., Lewandowski, G. \& Milchert, E., (2004). Technological parameters of the ammonolysis of waste 
1,2-dichloropropane, Journal of Hazardous Materials, 106(2-3), 107 - 114. DOI: 10.1016/j.jhazmat.2003.10.003 S03043894(03)00381-9

8. Bartkowiak, M., Lewandowski, G., Milchert, E. \& Pełech, R. (2006). Optimization of 1,2-diaminopropane preparation by the ammonolysis of waste 1,2-dichloropropane, Ind. Eng. Chem. Res. 45, 5681 - 5687. DOI: 10.1021/ie051134u.

9. Bartkowiak, M., Pełech, R. \& Milchert, E., (2006). Ammonolysis of (3-chloropropyl)trimethoxysilane, J. Hazard. Mater. 136(3), 854 - 858. DOI: 5317 10.1016/ j.jhazmat.2006.01.024 S0304-3894(06)00038-0.

10. Bartkowiak, M. \& Milchert, E., (2003). Properties and applications of 1,2-diaminopropane and polypropylenepolyamines, Przem. Chem. 82, 277 - 281.

11. Gustafson, D.L., Long, M.E., Thomas, R.S., Benjamin, S.A. \& Yang, R.S.H., (2000). Comparative Hepatocarcinogenicity of Hexachlorobenzene, Pentachlorobenzene, 1,2,4,5-Tetrachlorobenzene, and 1,4Dichlorobenzene: Application of a Medium-Term Liver Focus Bioassay and Molecular and Cellular Indices, Toxicological Sciences 53, 245 - 252.

12. Fathepure, B.Z., Tiedje, J.M. \& Boyd, S.A., (1988). Reductive dechlorination of hexachlorobenzene to tri- and dichlorobenzenes in anaerobic sewage sludge, Appl. Env. Microbiol. 54(2), 327-330. DOI: 0099-2240/88/020327-04\$02.00/0.

13. Booker, R.S. \& Pavlostathis, S.G., (2000). Microbial reductive dechlorination of hexachloro-1,3-butadiene in a methanogenic enrichment culture, Water Res. 34(18), 44374445. DOI:10.1016/S0043-1354(00)00214-1. 